\title{
Effect of particle size and surfactant on the solubility, permeability and dissolution characteristics of deferasirox
}

\author{
Tuğba GÜLSÜN 1 (D), Yağmur AKDAĞ ${ }^{1}(\mathbb{D}){\text { Nihan } \operatorname{IZAT}^{1} \text { (D), Levent ÖNER }}^{1} \mathbb{D}$, Selma ŞAHİN 1 * (D) \\ 1 Department of Pharmaceutical Technology, Faculty of Pharmacy, Hacettepe University, Ankara, Turkey. \\ * Corresponding Author. E-mail: sahin.selma@gmail.com (S.S.); Tel. +90-312-310 1524.
}

Received: 19 March 2019 / Revised: 11 April 2019 / Accepted: 13 April 2019

\begin{abstract}
Deferasirox is an oral iron chelator used for the treatment of chronic iron overload in blood transfusions. Deferasirox is a BCS Class II drug with low solubility and high permeability. In the formulation development stage for BCS Class II compounds, one of the main approaches is solubility enhancement to achieve better dissolution profiles, increased bioavailability and in some cases, dose reduction. The aim of the study was to investigate the effect of particle size and surfactant on the solubility, permeability and dissolution characteristics of deferasirox. Ball milling method was used to reduce the particle size of deferasirox. Pluronic F127 or sodium lauril sulfate (SLS) were selected as surfactants at different concentrations. The maximum increase in the solubility was obtained with $10 \%$ SLS at pH 1.2 (from $0.9 \mu \mathrm{g} / \mathrm{mL}$ to $333.7 \mu \mathrm{g} / \mathrm{mL}$ ), and with 5\% Pluronic F127 at pH 6.8 (from $46.8 \mu \mathrm{g} / \mathrm{mL}$ to $334.2 \mu \mathrm{g} / \mathrm{mL}$ ). Dissolution studies revealed that time to dissolve $85 \%$ of deferasirox was decreased as a function of ball milling time and particle size. Permeability studies showed that, in $100 \mu \mathrm{M}$ concentration, deferasirox permeability was significantly enhanced by all concentrations of SLS $(\mathrm{p}<0.05)$. With an increase in Pluronic F127 concentration, permeability of deferasirox was not altered $(p>0.05)$. All these results clearly demonstrated that surfactant addition to the formulations was effective for solubility enhancement of deferasirox, and surfactant type in optimized concentrations was very crucial. Particle size reduction can be used as a promising approach to improve dissolution, and hence bioavailability of deferasirox.
\end{abstract}

KEYWORDS: Deferasirox; dissolution; particle size distribution; permeability; solubility; surfactant.

\section{INTRODUCTION}

Oral absorption of drugs is a very complicated process, and affected by physicochemical properties of drugs (e.g. solubility, stability, pKa, lipophilicity, particle size, crystal form, permeability), properties of dosage forms (e.g., tablet, capsule, solution, suspension, emulsion) and also physiological properties of the gastrointestinal system (e.g. absorption mechanisms, gastrointestinal $\mathrm{pH}$ and blood flow, gastric emptying) [1].

Among the physicochemical properties, especially solubility, intestinal permeability and dissolution rate have a great impact on the absorption and hence the bioavailability of the drugs [2]. In this context, Amidon and his friends developed Biopharmaceutics Classification System (BCS) in 1995, and classified drugs into four categories based on their FDA solubility and permeability namely Class I (high solubility and high permeability), Class II (low solubility and high permeability), Class III (high solubility and low permeability), and Class IV (low solubility and low permeability) [3]. In 2005, Wu and Benet described Biopharmaceutics Drug Disposition Classification System (BDDCS) which is a modification of BCS. BDDCS and BCS differ in the criterion for permeability. According to BDDCS, metabolism is the major route of elimination for Class I and Class II compounds, whereas Class III and Class IV compounds are eliminated predominantly unchanged by renal and biliary routes [4].

Deferasirox (Figure 1) is an iron chelating agent used in the treatment of chronic iron overload caused by blood transfusions in both adults and pediatric patients [5]. According to the BCS and BDDCS, deferasirox is a Class II compound showing low solubility, high permeability, extensive metabolism and suspected to be substrates of efflux transporters (P-glycoprotein; Breast Cancer Resistance Protein; Multidrug Resistance Proteins) [6]. The critical parameter for deferasirox bioavailability is mainly its solubility. Solubility enhancement approaches can be implemented to increase the bioavailability of deferasirox and therefore, the dose, side effects and the overall production cost of deferasirox dosage forms can be reduced.

How to cite this article: Gülsün T, Akdağ Y, Izat N, Öner L, Şahin S. Effect of particle size and surfactant on the solubility, permeability and dissolution characteristics of deferasirox. J Res Pharm. 2019; 23(5): 851-859. 


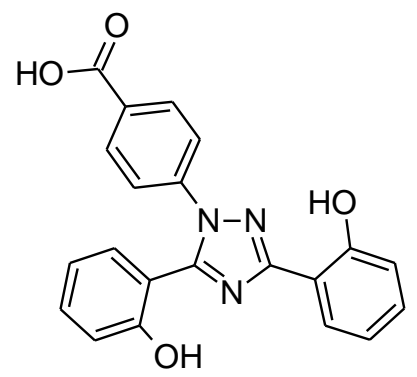

Figure 1. Chemical structure of deferasirox.

According to the FDA's BCS guidance, "a drug substance is considered highly soluble when the highest strength is soluble in $250 \mathrm{~mL}$ or less of aqueous media within the $\mathrm{pH}$ range of $1-6.8$ at $37 \pm 1^{\circ} \mathrm{C}^{\prime \prime}$ [7]. About $40 \%$ of drugs and drug candidates are poorly water soluble [8]. Hence, many methods have been developed to enhance solubility of a drug substance. These methods include particle size reduction, preparation of porous microparticles, preparation of solid dispersions, creating an inclusion complex, chemical modifications $(\mathrm{pH}$, salt), new formulation approaches (liposomes, niosomes, microemulsions), modification of crystal structure (polymorphism), addition of surfactants, addition of cosolvents, preparation of floating granules, using supercritical fluid and cryogenic technology [9-11].

"A drug substance is considered to be highly permeable when the systemic BA or the extent of absorption in humans is determined to be 85 percent or more of an administered dose based on a mass balance determination (along with evidence showing stability of the drug in the GI tract) or in comparison to an intravenous reference dose" according to BCS guidance of FDA [12]. In the literature, several approaches such as adding surfactant, preparing nanoemulsions, cyclodextrin inclusion complex, self-micro-emulsifying drug delivery systems (SMEDDS), self-double emulsifying drug delivery system (SDEDDS), mucoadhesive nanoparticles, prodrug, using chitosan derivatives, adding straight chain fatty acids and P-gp inhibition were suggested for the improvement of intestinal permeability of drugs [13].

Commercially, deferasirox is available in the market as 'tablets for oral suspension $(125,250,500 \mathrm{mg})$ ', 'oral tablets $(90,180,360 \mathrm{mg})$ ' and 'granules $(90,180,360 \mathrm{mg})$ '. Although 'tablets for oral suspension' dosage form of deferasirox contains sodium lauryl sulfate (SLS) and lactose, the other dosage forms do not contain SLS. The dose strength of deferasirox is reduced approximately 30\% in SLS-free but Pluronic-containing formulations.

The aim of the study was to enhance the solubility and permeability of deferasirox. For this purpose, both the effects of particle size and presence of surfactant on the permeability and saturation solubility, and particle size distribution on the dissolution behavior of deferasirox were evaluated.

\section{RESULTS AND DISCUSSION}

\subsection{Particle size distribution}

According to the Noyes-Whitney equation, dissolution rate of drug increases by increasing the surface area of drug with reducing the average particle size [14]. The particle size of deferasirox (d90) as a function of milling time was illustrated in Figure 2. The results clearly demonstrated that the particle size of deferasirox decreases with an increase in the milling time. Similar results can be found in the literature. Liversidge et al. showed that when aqueous dispersion of danazol with PVP as a stabilizer was milled, the weight average particle size was decreased from $10 \mu \mathrm{m}$ to $169 \mathrm{~nm}$, and its absolute bioavailability increased from $5.1 \pm 1.9 \%$ to $82.3 \pm 10.1 \%$ [15]. In another study, Jonghwi et al. reported that the mean particle size (d50) of naproxen decreased (from $13.7 \mu \mathrm{m}$ to $0.9 \mu \mathrm{m}$ ) with increasing grinding time (from 0 to 300s) [16]. Additionally, Niwa et al. prepared phenytoin nanosuspensions with PVP, PVA, SLS, HPC, HPMC, Tween 80 and their combinations by wet milling method. They found that in all nanosuspensions, particle size of phenytoin was decreased significantly [17]. All these studies in the literature supports our observations and indicates that particle size can be reduced significantly by milling method.

\subsection{Dissolution study}

Dissolution test is of great importance for formulation development and quality control of finished product. It is also utilized to evaluate bioequivalence of reference and generic products, show the similarity of pharmaceutical dosage forms, control in process and finished product specifications, and develop in vitro-in 
vivo correlations $[18,19]$. As recommended by FDA, $\mathrm{pH} 6.8$ phosphate buffer was used as dissolution medium for deferasirox. No surfactant was added to the dissolution medium to fully observe the effect of milling on dissolution of deferasirox [20].

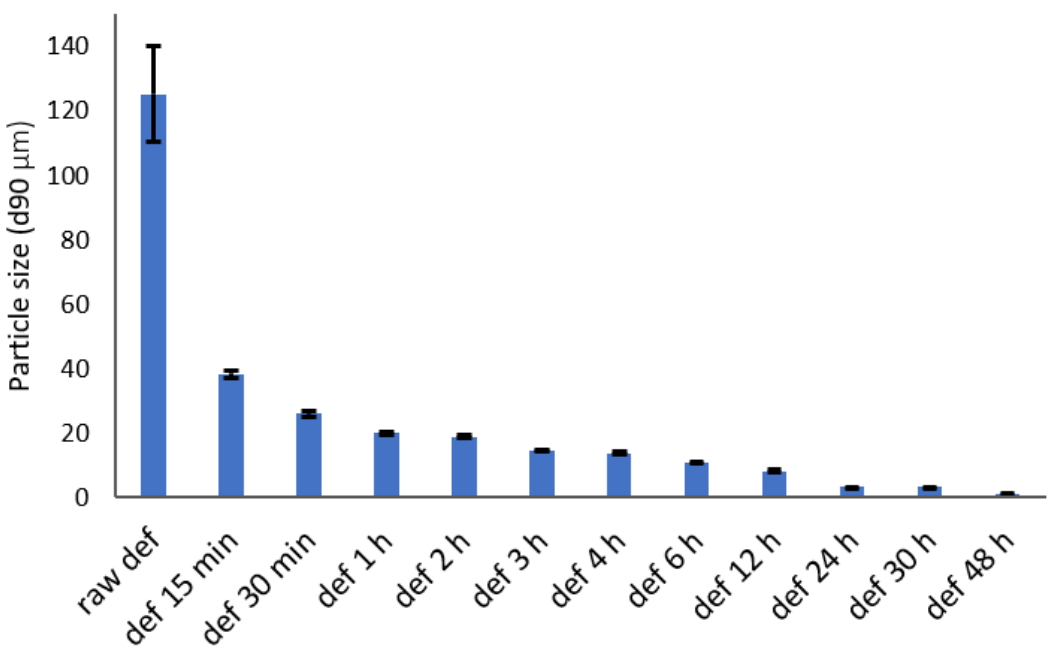

Figure 2. Particle size of deferasirox (def) $(\mathrm{d} 90 \mu \mathrm{m})$ as a function of ball milling time (mean $\pm S D, n=6)$.

Dissolution profiles of raw deferasirox powder and milled deferasirox suspensions with different particle size obtained with different milling times are given in Figure 3. It can be seen from the profile that time to dissolve $85 \%$ of deferasirox was influenced by the particle size. Although, $45 \mathrm{~min}$ is required to dissolve

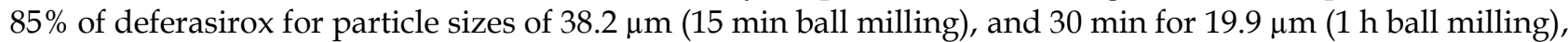
the corresponding time was only $10 \mathrm{~min}$ for particle size of $14.5 \mu \mathrm{m}$ ( $3 \mathrm{~h}$ ball milling), $10.6 \mu \mathrm{m}$ ( $6 \mathrm{~h}$ ball milling), $3.2 \mu \mathrm{m}(24 \mathrm{~h}$ ball milling) and $1.0 \mu \mathrm{m}$ ( $48 \mathrm{~h}$ ball milling). There was an enhancement in the dissolution rate of deferasirox from approximately $40 \mu \mathrm{m}$ to $15 \mu \mathrm{m}$ of particle size, whereas no significant difference was seen under the particle size of $10 \mu \mathrm{m}$. Approximately $10 \%$ of raw deferasirox was dissolved at the end of $90 \mathrm{~min}$. It can be seen clearly from the dissolution profiles that solubility of deferasirox was significantly enhanced $(\mathrm{p}<0.05)$ by milling (Figure 3 ).

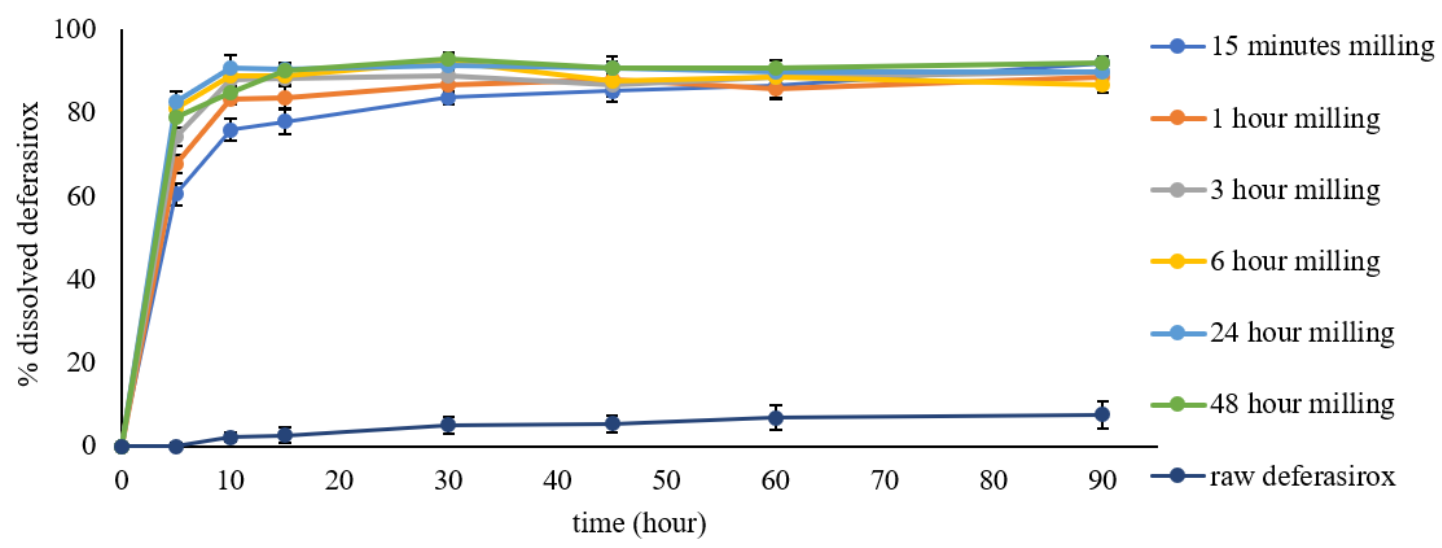

Figure 3. Dissolution profiles of raw deferasirox powder (d90: $125.16 \pm 14.81 \mu \mathrm{m})$ and milled deferasirox suspensions with different particle sizes (mean $\pm S D, n=3$ ).

Sun et al. prepared coenzyme Q10 nanocrystals with different particle sizes $(80 \mathrm{~nm}, 120 \mathrm{~nm}, 400 \mathrm{~nm}$, or $700 \mathrm{~nm}$ ) and investigated the in vitro dissolution of the nanosuspension formulations containing coenzyme Q10, and bulk drugs in three different dissolution media. The results obtained from these dissolution studies showed that dissolution rate of coenzyme Q10 was clearly affected by the particle size of drug [21]. In another study, Hecq et al. prepared nanoparticles of poorly water soluble drug nifedipine, by high pressure homogenization to enhance its solubility and dissolution rate. They reduced particle size of nifedipine 10 fold 
compared to the commercial product, increased surface area from 0.134 to $0.758 \mathrm{~m}^{2} / \mathrm{g}$, and consequently increased the dissolution rate [22]. All studies in the literature confirm the results of our study.

\subsection{Solubility study}

Surfactants may increase the solubility of substances by changing hydrophobicity, surface charge and surface tension. Because of these advantages, surfactants are therefore frequently used in the pharmaceutical field, in particular to increase solubility [23]. There are several studies in the literature demonstrating that solubilities of different active substances were increased in the presence of surfactants. For instance, Shokri et al. showed that surfactants such as cetrimonium bromide, SLS and Myrj 52 improved solubility of oxazepam [24]. Damian et al. demonstrated that the solubility of an antiviral agent (UC-781) increased in the presence of PEG 6000 or Gelucire 44/14 as surfactants [25]. Yüksel et al. reported that labrasol (surfactant with an HLB of 14) increased solubility of piroxicam [26].

In our study, solubility studies of deferasirox were performed at both $\mathrm{pH} 1.2$ and $\mathrm{pH} 6.8$ using different concentrations of Pluronic F127 or SLS. In the presence of surfactants, solubility of deferasirox was increased at both $\mathrm{pH}$. Effect of surface active agents on the solubility of deferasirox seemed to be $\mathrm{pH}$ dependent. At $\mathrm{pH}$ 1.2, SLS significantly increased the solubility of deferasirox more than Pluronic F127 at all concentrations $(\mathrm{p}<0.05$; Figure 4). On the other hand, at concentration levels of 1\%, $10 \%$ and $20 \%$, Pluronic F127 significantly increased solubility of deferasirox more than SLS at $\mathrm{pH} 6.8$ which represents intestinal $\mathrm{pH}$. The most dramatic difference in deferasirox solubility (about 6 -fold, $\mathrm{p}<0.05$ ) at $\mathrm{pH} 6.8$ was obtained in the presence of $1 \%$ Pluronic F127 in comparison to SLS.

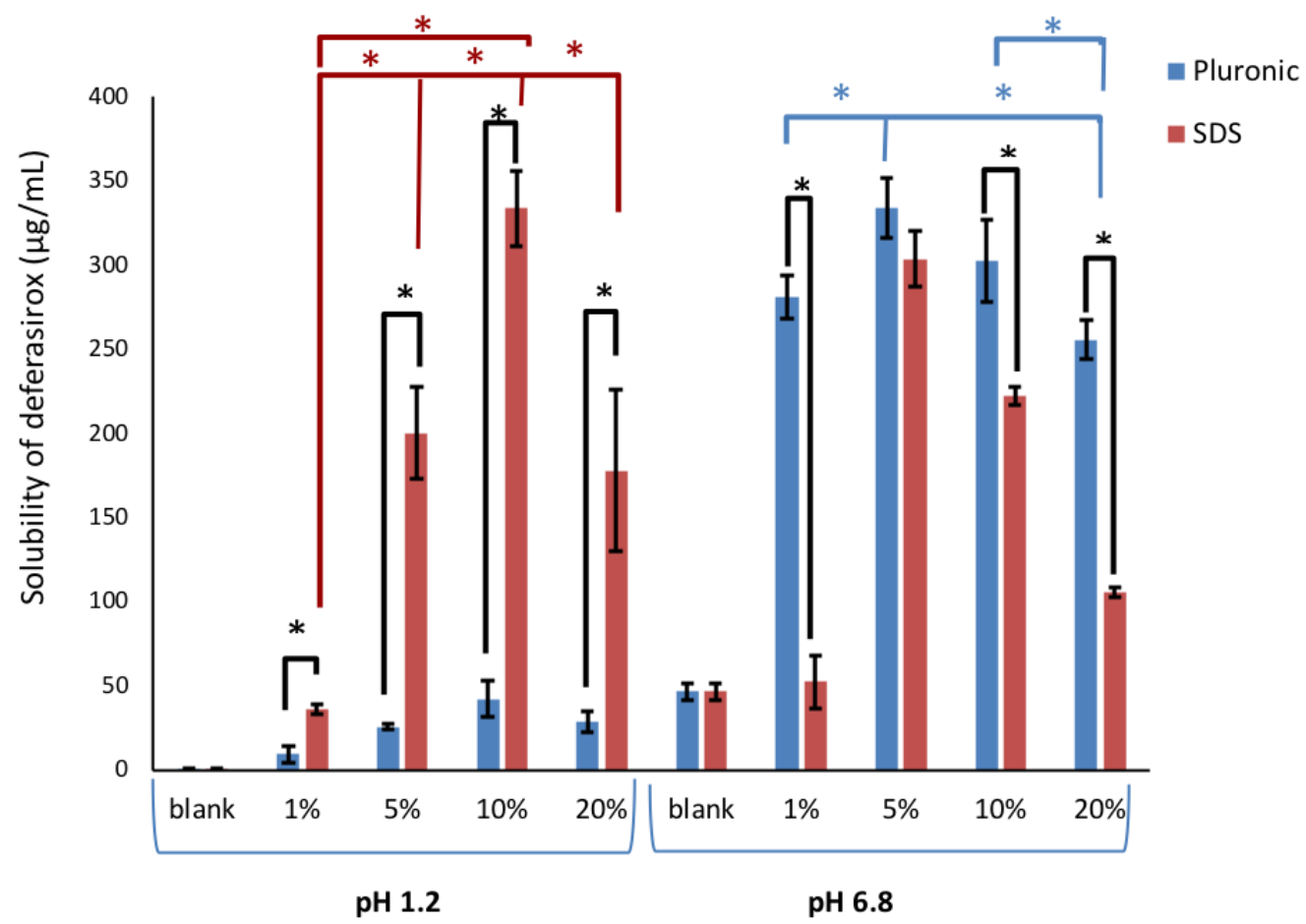

Figure 4. Effect of surfactants on the solubility of raw deferasirox (d90: $125.16 \pm 14.81 \mu \mathrm{m})$ at $\mathrm{pH} 1.2$ and $\mathrm{pH}$ 6.8 buffers (mean $\pm S D, n=3)$ ( ${ }^{*}$ indicates statistical significance $\left.\mathrm{p}<0.05\right)$.

The solubility and hence bioavailability of deferasirox is low. Therefore, in the literature, various approaches are used to increase the bioavailability of deferasirox by increasing its solubility. Goswami et al. were synthesized the deferasirox-TAT(47-57) peptide conjugate to obtain water soluble alternatives of deferasirox, and also better efficacy to chelate brain iron. It was reported that solubility of deferasirox was increased from $<1 \mathrm{mg} / \mathrm{mL}$ to $>10 \mathrm{mg} / \mathrm{mL}$ [27]. In our study, maximum solubility increase was obtained with $10 \%$ SLS at pH 1.2 (from $0.9 \mu \mathrm{g} / \mathrm{mL}$ to $333.7 \mu \mathrm{g} / \mathrm{mL}$ ), and with 5\% Pluronic F127 at pH 6.8 (from $46.8 \mu \mathrm{g} / \mathrm{mL}$ to $334.2 \mu \mathrm{g} / \mathrm{mL})$. 


\subsection{Permeability study}

Evaluation of permeability across Caco-2 cells are widely used to make prediction about the intestinal absorption of active pharmaceutical ingredients, and also potential effect of excipients on the permeability of compounds. Yee et al. reported that compounds with a $P_{\text {app }}$ values greater than $1 \times 10^{-5} \mathrm{~cm} / \mathrm{s}$ can be classified as a well absorbed (70-100\%) compounds [28]. In the literature, the apical-to-basolateral $\mathrm{P}_{\text {app }}$ value of deferasirox $(500 \mu \mathrm{M})$ across Caco-2 cells $\left(1.66 \pm 0.13 \times 10^{-5} \mathrm{~cm} / \mathrm{s}\right.$; [29]) was very similar to our permeability results $\left(1.38 \pm 0.14 \times 10^{-5} \mathrm{~cm} / \mathrm{s}, 1.03 \pm 0.16 \times 10^{-5} \mathrm{~cm} / \mathrm{s}\right.$ for 50 and $100 \mu \mathrm{M}$, respectively). All these values indicate that deferasirox is a well-absorbed compound [30]. In addition, in the regulatory scientific papers, deferasirox was identified as a highly permeable compound (intrinsic permeability $>80 \%$ ) based on the in vitro Caco-2 studies [31], confirming our results.

Permeability studies revealed that, as a function of deferasirox concentration (50 and $100 \mu \mathrm{M})$, permeability value of deferasirox changed significantly $(\mathrm{p}<0.05$; Figure 5$)$. Deferasirox permeability was not influenced with the addition of Pluronic F127 as compared to raw deferasirox. Although, in $100 \mu \mathrm{M}$ concentration, deferasirox permeability was significantly enhanced by all concentrations of SLS ( $p<0.05)$, in 50 $\mu \mathrm{M}$ concentration, deferasirox permeability was increased by only $0.5 \%$ SLS when compared to raw deferasirox. On the other hand, with an increase in Pluronic F127 concentration, the difference between deferasirox concentrations was disappeared ( $p>0.05$; Figure 5).

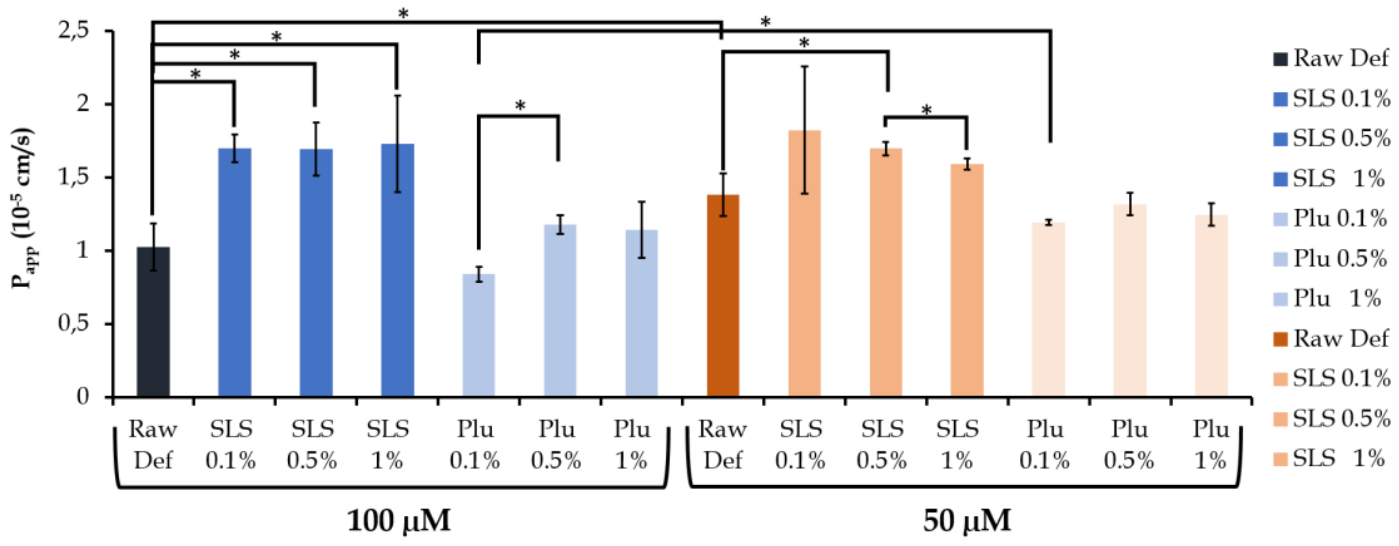

Figure 5. Effect of surfactants on the permeability of raw deferasirox (d90: 125.16 $\pm 14.81 \mu \mathrm{m})(\mathrm{mean} \pm \mathrm{SD}$, $\mathrm{n}=3$ ). (Raw Def: untreated deferasirox, Plu: Pluronic F127) ( ${ }^{*}$ indicates statistical significance $\left.\mathrm{p}<0.05\right)$.

Increasing the permeability of an active ingredient by adding surfactant to the formulation is a known and common method. However, deferasirox is a high permeable compound, and it was confirmed by present study that the effect of surfactants is mainly on its solubility rather than permeability.

\subsection{HPLC analysis}

Quantitative analysis of deferasirox from dissolution, solubility and permeability samples were performed by a simple and reliable HPLC method. Determination coefficient $\left(R^{2}\right)$ values were over 0.999 indicating linearity of the method. Also, HPLC method used was considered selective as there was no interfering peak with the retention time of deferasirox.

\section{CONCLUSION}

Deferasirox is a BCS Class II drug, the critical parameter for bioavailability is therefore, its solubility. As commercially available deferasirox tablets have surfactants (SLS, Pluronic F127), this study was designed to investigate the effects of these surfactants on the permeability and saturation solubility of deferasirox. Further, effect of particle size on the dissolution time of deferasirox was also investigated. Solubility results showed that the influence of SLS on deferasirox solubility especially at $\mathrm{pH} 1.2$, was more pronounced than those of Pluronic F127. However, at $\mathrm{pH}$ 6.8, Pluronic F127 increased solubility of the deferasirox more than SLS especially at $1 \%$ concentration. Since deferasirox has already high permeability, surfactants did not increase its permeability across Caco-2 cell monolayer. The results of permeability studies demonstrated that Pluronic 
F127 has no advantage over SLS in regard to enhancement of permeability. Dissolution rate of deferasirox was increased by reducing the particle size. All these results imply that dissolution rate of poorly water-soluble drugs may be improved by decreasing the particle size with an efficient and simple method like ball milling.

\section{MATERIALS AND METHODS}

\subsection{Materials}

Deferasirox was obtained from Neuland Labs. (India). Pluronic F127 was obtained from Uniqema (Belgium). Sodium lauryl sulfate (SLS) was purchased from Sigma Aldrich (Germany). Hank's balanced salt solution (HBSS), fetal bovine serum (FBS) and Dulbecco's Modified Eagle's Medium (DMEM) were all obtained from Biochrom AG (Germany), and ThincertsTM cell culture inserts $(0.4 \mu \mathrm{m})$ from Grenier Bio-one (Germany). Penicillin-Streptomycin solution was acquired from Life Technologies, Inc. (USA). All other chemicals were of analytical grade.

\subsection{Methods}

\subsubsection{Particle size reduction}

Particle size of bulk deferasirox was decreased by ball milling method. Aqueous suspension of deferasirox (1\%) was milled at $300 \mathrm{rpm}$ using 25 agate balls with $10 \mathrm{~mm}$ in diameter. Samples were collected at $15 \mathrm{~min}, 30 \mathrm{~min}, 1 \mathrm{~h}, 2 \mathrm{~h}, 3 \mathrm{~h}, 4 \mathrm{~h}, 6 \mathrm{~h}, 12 \mathrm{~h}, 24 \mathrm{~h}, 30 \mathrm{~h}, 48 \mathrm{~h}$ intervals and vortexed for a further $1 \mathrm{~min}$. Particle size distributions of these samples were measured by a Malvern Mastersizer 2000.

\subsubsection{Dissolution study}

Based on the particle size distribution results, deferasirox suspensions obtained after $15 \mathrm{~min}, 1 \mathrm{~h}, 3 \mathrm{~h}, 6$ $\mathrm{h}, 24 \mathrm{~h}$ and $48 \mathrm{~h}$ ball milling were chosen for in vitro dissolution studies. To evaluate the effect of particle size on the dissolution rate, no surfactant was added to the dissolution medium. The sink condition was provided in all dissolution experiments. The dissolution studies were carried out at $\mathrm{pH} 6.8$ phosphate buffer $(900 \mathrm{~mL})$ utilizing the USP apparatus II (pedal) method $\left(50 \mathrm{rpm}, 37 \pm 0.5^{\circ} \mathrm{C}\right)$ using a SOTAX dissolution apparatus as recommended by the FDA [20]. Two $\mathrm{mL}$ samples were withdrawn from the dissolution medium at 5, 10, 15, $30,45,60$ and $90 \mathrm{~min}$, and then equal volume of fresh medium was added to maintain a constant total volume. Concentrations of deferasirox in the samples were measured by an RP-HPLC method. Dissolved percent of deferasirox values were plotted against the corresponding sampling times.

\subsubsection{Saturation solubility}

The saturation solubilities of raw deferasirox $(\mathrm{d} 90$ : $125.16 \pm 14.81 \mu \mathrm{m})$ were determined at two different media ( $\mathrm{pH} 1.2$ and $\mathrm{pH} 6.8$ ) with the addition of Pluronic F127 or SLS at four different concentrations $(1 \%, 5 \%$, $10 \%, 20 \%)$. Excess amount of deferasirox was added in to the buffer solutions and agitated in a horizontal laboratory shaker with $80 \mathrm{rpm}$ at $37 \pm 2^{\circ} \mathrm{C}$ for $24 \mathrm{~h}$. Samples were withdrawn $24 \mathrm{~h}$ after the start of experiment, and filtered through a membrane filter $(0.45 \mu \mathrm{m})$ prior to analysis. The amount of drug dissolved were analyzed using an RP-HPLC method.

\subsubsection{Permeability study}

Caco-2 cells (passage number 26-30) were used for determination of raw deferasirox ( $d 90: 125.16 \pm 14.81$ $\mu \mathrm{m})$ permeability. The cells were seeded on 12-well plates (60.000 cells/well, ThinCerts $\left.{ }^{\mathrm{TM}}\right)$, and used for transport studies 21 days after seeding. Cells were cultured in a humidified incubator at $37^{\circ} \mathrm{C}$ and $5 \% \mathrm{CO}_{2}$ atmosphere (Sanyo, Osaka, Japan). The culture medium was changed every other day for 21 days. The growth medium was Dulbecco's Modified Eagle's Medium supplemented with $10 \%$ fetal bovine serum, penicillin (50 unit $/ \mathrm{mL})$ and streptomycin $(50 \mu \mathrm{g} / \mathrm{mL})$. Before the transport experiments, transepithelial electrical resistance (TEER) values were measured using Millicell-ERS voltohmmeter (USA), and the cells with TEER values $>600$ $\Omega . \mathrm{cm}^{-2}$ were used for permeability studies. The transport buffer (TB) was HBSS containing $25 \mathrm{mM}$ D-glucose and $10 \mathrm{mM}$ HEPES. For evaluation of concentration-dependent permeability characteristics of deferasirox, permeability studies were performed at two different concentrations (50 and $100 \mu \mathrm{M})$. Deferasirox (50 and 100 $\mu \mathrm{M}$ ) was dissolved in TB containing Pluronic F127 or SLS in concentrations of $0.1 \%, 0.5 \%$ and $1 \%$, and then added to the apical side $(500 \mu \mathrm{L})$. Only TB $(1500 \mu \mathrm{L})$ was added to basolateral side. At the end of 2-hour incubation $\left(37^{\circ} \mathrm{C}\right.$ and $\left.30 \mathrm{rpm}\right)$, samples from both apical and basolateral sides were removed, and 
concentrations in samples were analyzed by means of an RP-HPLC method. The permeability $\left(\mathrm{P}_{\text {app }}\right)$ values were calculated using following equation (Eq. 1).

$$
\mathrm{P}_{\mathrm{app}}=\left(\mathrm{V}_{\mathrm{b}} \mathrm{C}_{\mathrm{b}}\right) /\left(\mathrm{C}_{0} \mathrm{AT}\right)
$$

where $\mathrm{V}_{\mathrm{b}}$ is volume of transport buffer at basolateral side $\left(\mathrm{cm}^{3}\right), \mathrm{C}_{\mathrm{b}}$ is concentration of the drug at basolateral side $(M), C_{0}$ is initial concentration of the drug in the apical side $(M), A$ is the surface area of insert $\left(1.131 \mathrm{~cm}^{2}\right)$, and $\mathrm{T}$ is time period of experiment(s).

\subsubsection{HPLC method}

The used HPLC analyzes were based on the HPLC method developed and validated by Anandakumar et al. [32]. An HPLC system (Shimadzu LC-20 A/Prominence Alliance; Japan) and a Waters Spherisorb ODS2 C18 $(250 \times 4.6 \mathrm{~mm} 5 \mu \mathrm{m}$; USA) column were used for quantitative analyses of deferasirox isocratically. Acetonitrile:water mixture $(70: 30 \mathrm{v} / \mathrm{v})$ adjusted to $\mathrm{pH} 3.5$ with orthophosphoric acid was used as the mobile phase at a flow rate of $2 \mathrm{~mL} / \mathrm{min}$, with a 7-min total run time at room temperature. The injection volume was $20 \mu \mathrm{L}$ and detection was performed with a DAD detector at $232 \mathrm{~nm}$. The column temperature was maintained at room temperature.

\subsubsection{Statistical analysis}

The results were compared with Mann-Whitney U test using GraphPad Prism 6. The difference between the results was considered significant, when $p$ value was less than 0.05 .

Acknowledgements: Nihan Izat is supported by TUBITAK 2211 grant.

Author contributions: Concept - L.O., S.S.; Design - T.G., Y.A., N.I., L.O., S.S.; Supervision -L.O., S.S.; Materials - T.G., Y.A., N.I., L.O., S.S.; Data Collection and/or Processing - T.G., Y.A., N.I., L.O., S.S.; Analysis and/or Interpretation T.G., Y.A., N.I.; Literature Search - T.G., Y.A., N.I., L.O., S.S.; Writing - T.G., Y.A., N.I., L.O., S.S.; Critical Reviews T.G., Y.A., N.I., L.O., S.S.

Conflict of interest statement: The authors declared no conflict of interest.

\section{REFERENCES}

[1] Dahan A, Miller JM, Amidon GL. Prediction of solubility and permeability class membership: Provisional BCS classification of the world's top oral drugs. AAPS J. 2009; 11(4): 740-746. [CrossRef]

[2] Khadka P, Ro J, Kim H, Kim I, Kim JT, Kim H, Cho JM, Yun G, Lee J. Pharmaceutical particle technologies: An approach to improve drug solubility, dissolution and bioavailability. Asian J Pharm Sci. 2014; 9(6): $304-316$. [CrossRef]

[3] Amidon GL, Lennernäs H, Shah VP, Crison JR. A theoretical basis for a biopharmaceutics drug classification: The correlation of in vitro drug product dissolution and in vivo bioavailability. Pharm Res. 1995; 12(3): 413-420. [CrossRef]

[4] Wu C-Y, Benet LZ. Predicting drug disposition via application of BCS: Transport/absorption/elimination interplay and development of a biopharmaceutics drug disposition classification system. Pharm Res. 2005; 22(1): 11-23. [CrossRef]

[5] Vichinsky E, Onyekwere O, Porter J, Swerdlow P, Eckman J, Lane P, Files B, Hassell K, Kelly P, Wilson F. A randomised comparison of deferasirox versus deferoxamine for the treatment of transfusional iron overload in sickle cell disease. Br J Haematol. 2007; 136(3): 501-508. [CrossRef]

[6] Hosey CM, Chan R, Benet LZ. BDDCS predictions, self-correcting aspects of BDDCS assignments, BDDCS assignment corrections, and classification for more than 175 additional drugs. AAPS J. 2016; 18(1): 251-260. [CrossRef]

[7] Guidance for industry. Waiver of in vivo bioavailability and bioequivalence studies for immediate-release solid oral dosage forms based on a biopharmaceutics classification system. U.S. Department of health and human services food and drug administration center for drug evaluation and research (CDER). 2017. https://www.fda.gov/downloads/Drugs/Guidances/ucm070246.pdf (accessed March 16, 2019).

[8] Williams HD, Trevaskis NL, Charman SA, Shanker RM, Charman WN, Pouton CW, Porter CJ. Strategies to address low drug solubility in discovery and development. Pharmacol Rev. 2013; 65(1): 315-499. [CrossRef] 
[9] Chaudhary A, Nagaich U, Gulati N, Sharma V, Khosa R, Partapur M. Enhancement of solubilization and bioavailability of poorly soluble drugs by physical and chemical modifications: A recent review. J Adv Pharm Educ Res. 2012; 2(1): 32-67.

[10] Hetal T, Bindesh P, Sneha T. A review on techniques for oral bioavailability enhancement of drugs. Health. 2010; 4(3): 033.

[11] Kumar A, Sahoo SK, Padhee K, Kochar P, Sathapathy A, Pathak N. Review on solubility enhancement techniques for hydrophobic drugs. Pharm Glob. 2011;3(3): 001-007.

[12] FDA, Waiver of in vivo bioavailability and bioequivalence studies for immediate-release solid oral dosage forms based on a biopharmaceutics classification system guidance for industry. https://www.fda.gov/downloads/drugs/guidances/ucm070246.pdf (accessed March 1, 2019).

[13] Shaikh M, Derle ND, Bhamber R. Permeability enhancement techniques for poorly permeable drugs: A review. J Appl Pharm Sci. 2012; 2(6): 34-39. [CrossRef]

[14] Noyes AA, Whitney WR. The rate of solution of solid substances in their own solutions. J Am Chem Soc. 1897; 19(12): 930-934.

[15] Liversidge GG, Cundy KC. Particle size reduction for improvement of oral bioavailability of hydrophobic drugs: I. Absolute oral bioavailability of nanocrystalline danazol in beagle dogs. Int J Pharm. 1995; 125(1): 91-97. [CrossRef]

[16] Lee J, Lee S-J, Choi J-Y, Yoo JY, Ahn C-H. Amphiphilic amino acid copolymers as stabilizers for the preparation of nanocrystal dispersion. Eur J Pharm Sci. 2005; 24(5): 441-449. [CrossRef]

[17] Niwa T, Miura S, Danjo K. Universal wet-milling technique to prepare oral nanosuspension focused on discovery and preclinical animal studies-development of particle design method. Int J Pharm. 2011; 405(1-2): 218-227. [CrossRef]

[18] O'Hara T, Dunne A, Butler J, Devane J. A review of methods used to compare dissolution profile data. Pharm Sci Technolo Today. 1998; 1(5): 214-223. [CrossRef]

[19] Ozturk N, Kaynak MS, Sahin S. Comparison of dissolution profiles of commercially available lamivudine tablets. Dissolut Technol. 2015; 22(4): 38-43. [CrossRef]

[20] FDA, Dissolution methods. https://www.accessdata.fda.gov/scripts/cder/dissolution/dsp_searchresults.cfm (accessed March 1, 2019).

[21] Sun J, Wang F, Sui Y, She Z, Zhai W, Wang C, Deng Y. Effect of particle size on solubility, dissolution rate, and oral bioavailability: Evaluation using coenzyme q10 as naked nanocrystals. Int J Nanomedicine. 2012; 7: 5733. [CrossRef]

[22] Hecq J, Deleers M, Fanara D, Vranckx H, Amighi K. Preparation and characterization of nanocrystals for solubility and dissolution rate enhancement of nifedipine. Int J Pharm. 2005; 299(1-2): 167-177. [CrossRef]

[23] Sharma D. Solubility enhancement strategies for poorly water-soluble drugs in solid dispersions: A review. Asian J Pharm. 2007; 1(1): 9-19.

[24] Shokri J, Azarmi S, Sabouri A, Shokri M. Enhancement of oxazepam dissolution rate using oxazepam-surfactant solid dispersions. Pharm Sci. 2006; (4): 35-45.

[25] Damian F, Blaton N, Naesens L, Balzarini J, Kinget R, Augustijns P, Van den Mooter G. Physicochemical characterization of solid dispersions of the antiviral agent uc-781 with polyethylene glycol 6000 and gelucire 44/14. Eur J Pharm Sci. 2000; 10(4): 311-322. [CrossRef]

[26] Yüksel N, Karataş A, Özkan Y, Savaşer A, Özkan SA, Baykara T. Enhanced bioavailability of piroxicam using gelucire 44/14 and labrasol: In vitro and in vivo evaluation. Eur J Pharm Biopharm. 2003; 56(3): 453-459. [CrossRef]

[27] Goswami D, Vitorino HA, Alta RYP, Silvestre DM, Nomura CS, Machini MT, Espósito BP. Deferasirox-tat(47-57) peptide conjugate as a water soluble, bifunctional iron chelator with potential use in neuromedicine. BioMetals. 2015; 28(5): 869-877. [CrossRef]

[28] Yee S. In vitro permeability across caco-2 cells (colonic) can predict in vivo (small intestinal) absorption in man factor myth. Pharm Res. 1997; 14(6): 763-766.

[29] Huang X-P, Spino M, Thiessen J. Transport kinetics of iron chelators and their chelates in caco-2 cells. Pharm Res. 2006; 23(2): 280-290. [CrossRef]

[30] Debebe Z, Nekhai S, Ashenafi M, Lovejoy DB, Kalinowski DS, Gordeuk VR, Byrnes WM, Richardson DR, Karla PK. Development of a sensitive hplc method to measure in vitro permeability of e-and z-isomeric forms of thiosemicarbazones in caco-2 monolayers. J Chromatogr B. 2012; 906: 25-32. [CrossRef] 
[31] https://www.ema.europa.eu/en/documents/scientific-discussion/exjade-epar-scientific-discussion_en.pdf (accessed on April 3, 2019).

[32] Anandakumar K, Chinthala R, Subhash V, Jayamariappan M. Development and validation of newer analytical methods for the estimation of deferasirox in bulk and in tablet dosage form by UV spectroscopy and RP-HPLC. J Pharm Res. 2011; 4: 2998-3000.

This is an open access article which is publicly available on our journal's website under Institutional Repository at http://dspace.marmara.edu.tr. 